\title{
Environmental information systems based on physical flows
}

\author{
A.J.D. Lambert, M.H. Jansen, R.V. Schuwer, M.A.M. Splinter \\ Eindhoven University of Technology, Graduate School of Industrial Engineering and \\ Management Science, Paviljoen, PO Box 513, NL-5600MB Eindhoven, The Netherlands; \\ phone +3140 247 2952; fax +3140 2432 612; \\ e-mail \{m.h.jansen; a.j.d.lambert; r.v.schuwer; m.a.m.splinter\}@tm.tue.nl
}

\begin{abstract}
This paper deals with the basic aspects of environmental information systems and advocates their integration in the information systems that already exist in companies, especially those focused on production control. A strong emphasis is on the central role of physical information, i.e. material and energy flows. A multiple-input multiple-output physical-flow model is proposed to be the standard module for describing the whole range of primary industrial processes and the basic reference to information related to production. It is concluded that the logic consequence of integrating environmental information in the existing information system results in a production oriented information infrastructure concept, in which environmental information is an integral part rather than an extension. This serves clearness and flexibility of the information system and will be profitable to the core activities of the company as well.
\end{abstract}

\section{Keywords}

Sustainable production, environmental information systems, physical flow information

\section{$1 \quad$ INTRODUCTION}

Growing environmental concern has encouraged consciousness on resources, waste and emissions. Concepts like sustainablility and industrial ecology (Graedel and Allenby, 1995) are increasingly applied. However, also a number of leading edge manufacturers are viewing environmental improvement as a means to competitive advantage, usually as part of Total Quality Management initiatives. Benefits can be obtained from cost reductions in energy use, materials and packaging, less waste disposal and reduced regulatory burdens, but also from increased production efficiencies, marketing opportunities -green image- and balanced product design (AMR, 1994). To meet these requirements, it is indispensable to generate and exchange an ever increasing and changing amount of environmental information with respect to products and production processes. Most of this information is based on physical flows.

Existing Enterprise Resource Planning (ERP)-systems on company level are focused on production control and support operational and tactical functions like cost accounting, capacity and resource planning, stock control and quality management. Although these functions are, in principle, also related to information on physical flows, their integration with environmental functionality is not performed in practice. 


\subsection{Environmental, physical and production data}

The discrepancy between the environmental and production point-of-view originates from history, the first minimizing environmentally harmful flows and the latter optimizing the timeliness-locationquantity relation. Additionally, a gap between flow and discrete production has been grown over the years. Both features have led to different approaches in process description. In discrete manufacturing, bills-of-material are applied which describe the composition of intermediate and final products in terms of parts and modules. In process industries, recipes are applied, which describe the ingredients and process parameters. Often a recipe admits variation and, in general, multiple inputs and outputs are present.

The latter property however, is not confined to the process industry. This can be made clear if waste and emissions of a production process are considered as -though undesired- products. In this paper, the starting point is a single view on process modeling, which is of crucial importance to close the gap. Recent examples of the existing, non-integrated, viewpoints are, e.g.(Nemerow, 1995) with respect to the process industry, (Inoue et al, 1992) with respect to discrete manufacturing and assembly and (Wang and Johnson, 1995; Wong et al, 1993; Lambert, 1995) with emphasis on product recycling.

In integrating environmental information in production control systems, one is faced with the essential role of physical quantities in virtually each functionality. Therefore, a novel approach in production systems is required, by restructuring these systems in such a way that the primary (material transforming) process and its derived physical flow model play a central role. This will be elaborated in this paper. The first step in the analysis is the translation from the stated environmental requirements into physical flows concepts; the second step covers the translation of those concepts into specifications for process registration.

\subsection{Structure of the paper}

The starting point of this paper -section 2- is formed by the analysis of environmental requirements (2.1) and the applied concept behind physical flows: the mass and energy balance (2.2). Their mutual relationship is made clear by an example from automotive industries, taken from (Langeveld, 1995), in section 2.3. The information requirements for environmental information systems, resulting from the mass and energy balance, are expressed in the concept of a multiple-input multiple-output process approach and further detailed in an information infrastructure -section 3-. This section is concluded with a datamodel and evaluation to cover the above mentioned concept. Finally, some conclusions are established and recommendations for further research are presented.

\section{THE TRANSLATION OF ENVIRONMENTAL REQUIREMENTS INTO THE CONCEPT OF MASS AND ENERGY FLOWS}

\subsection{Environmental requirements}

Starting a systematic approach of environmental information systems, environmental impact should be clearly specified. It is usually subdivided in four categories, viz.: (1) exhaustion of resources, (2) waste and emissions, (3) nuisance, (4) occupation and modification (in particular: impoverishment) of the natural environment.

Occupation and impoverishment, although being of crucial importance, are difficult to quantify and consequently not quantitatively related to production. Nuisance is truly important to 
companies with respect to image and claims because complaints are frequently related to it. Nuisance, however, is locally experienced, not directly related to production and possesses a mainly subjective character, inflicting neither considerable nor persistent damage to the eco-system.

Utilization of exhaustible resources and discharge of matter and energy to the ecosystem are closely interconnected due to mass and energy conservation. Moreover, they are relatively unambiguously quantifiable and directly related to production. Although determination of quantitative relationships between discharge of physical flows and environmental impact still remains complex and can often be performed only ambiguously, agreements on this topic have been made and standards have been established so these will usually be accepted for validation of the environmental information that has been made available (Guineé et al, 1993ab). The very essential of environmental information, however, is related to the physical flows within and through the company.

\subsection{Physical flows}

Production chains comprise the trajectory from extraction (mining, agriculture) up to a desired level of production (e.g.: materials production); product chains involve the physical flow through the techno-system from cradle (extraction) to grave (discharge), thus consisting of the phases: extraction, production, consumption, upgrading, disposal. The production phase can coarsely be subdivided in about three sub-phases, often carried out by different companies, namely:

1. Materials production (process industry), the creation of internal characteristics;

2. Parts production (discrete production), the creation of external characteristics;

3. Final production (assembly), the creation of complex functionality.

Increasing importance of product recycling and the establishment of techniques like life cycle assessment (LCA) -that in the near future will be standardized into detail in the ISO 14000 series, see (ISO, 1992,1994)- results in a growing demand on environmental information that is related to the total product life-cycle and thus to the physical flows. Although LCA considers usually only partial material flows -referring to those substances that may cause environmental harm-, requirements on flexibility and generality lead to the preference of founding the environmental information system on the complete physical flow scheme on company and/or product chain level. The degree of detail of such a scheme can then more easily be adapted to a variety of requirements. Favoring appropriate

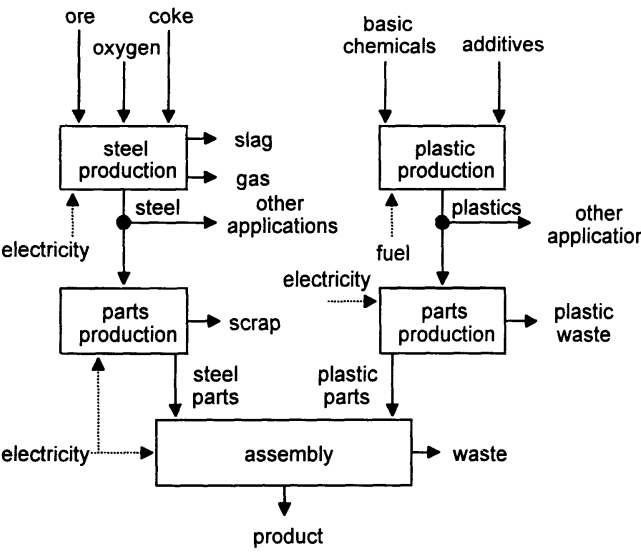

Figure 1. Process-product chain. data-exchange between the different links of a chain, the data should be structured in a generic way, without essential distinction between particular production types like materials processing, parts processing and assembly. The product chain actually consists of an alternation of processes and products, a so-called process-product chain (Kandelaars et al, 1996). In figure 1, a highly aggregated example of a part of such a chain is presented for the automotive industry. It is seen that both process and product level are characterized by combinations of convergence and divergence. Actually, both energy use and environmental effects caused by emissions intrinsically lead to divergence, even when 
the process is strictly convergent, like in assembly. This approach is the opposite of the linear or convergent tree-like structures that are commonly applied in modeling of discrete manufacturing or assembly, and in standard LCA.

There is a direct relation between local and chain aspects: information on the physical flows is supplied by local organizations. To accomplish this, material flows are subdivided according to their composition e.g. by elements, compounds, materials, families of parts (e.g. printed circuit boards), parts or modules. In general, completeness of data on composition, like the complete subdivision in elements, is not mandatory. Only data on some critical elements (e.g. cadmium) or compounds (e.g. $\mathrm{SO}_{2}$ ) are required. For logistic purposes, only the subdivision into parts as given by the BOM is needed, without data on composition. A correspondence between those viewpoints is highly preferable.

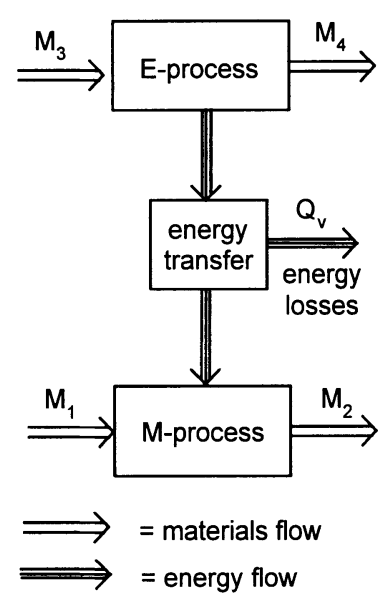

\subsection{Mass and energy balances}

The above mentioned view results in a conceptual model for physical flows that will be used as basis of the environmental and information model (Splinter, 1994) (figure 2). The main idea is that a production system is considered as a combination of two transformation processes. Energy carriers are transformed (E-process). The energy thus released is transferred and applied to the transformation of the materials flow, i.e. the proper production process (M-process). Two entering flows can be distinguished: $M_{1}$, entering the $M$-process and $\mathrm{M}_{3}$, entering the E-process. At the output side, three leaving flows are discerned: used energy carriers $\left(\mathrm{M}_{4}\right)$, transfer losses $\left(\mathrm{Q}_{\mathrm{v}}\right)$, and the leaving flow $\mathrm{M}_{2}$ that can be subdivided in a product flow and an undesired flow that may cause environmental harm. Due to mass and energy conservation, the total entering mass and energy flows equal the leaving ones, respectively. This enables the derivation of mass and energy balances.

Figure 2. The relationship between energy and manufacturing process.

\subsection{Example from automotive industry}

The car manufacturer "CAR-E" desires to obtain environmental information on the complex production process and starts with a study on its engine spray cabin (figure 3 ) because it is expected that this represents the essential aspects of environmentally relevant processes. The engines are subject to three main processes: cleaning, spraying, and drying.

With respect to the above defined input, the following typology of flows is applied:

1. Materials flows:

- Proportional to production level; the relevant quantity to coating is the external surface in $\mathrm{m}^{2}$ of the engine. Its relationship with the engine's weight in $\mathrm{kg}$ depends on its type. The type of coating also depends on the engine's type.

- Independent of production but proportional to time; cleaning operations occur according to a pre-determined schedule, e.g. each two weeks, independent of the level of the production.

2. Energy flows: in this case they are essentially proportional to time. 


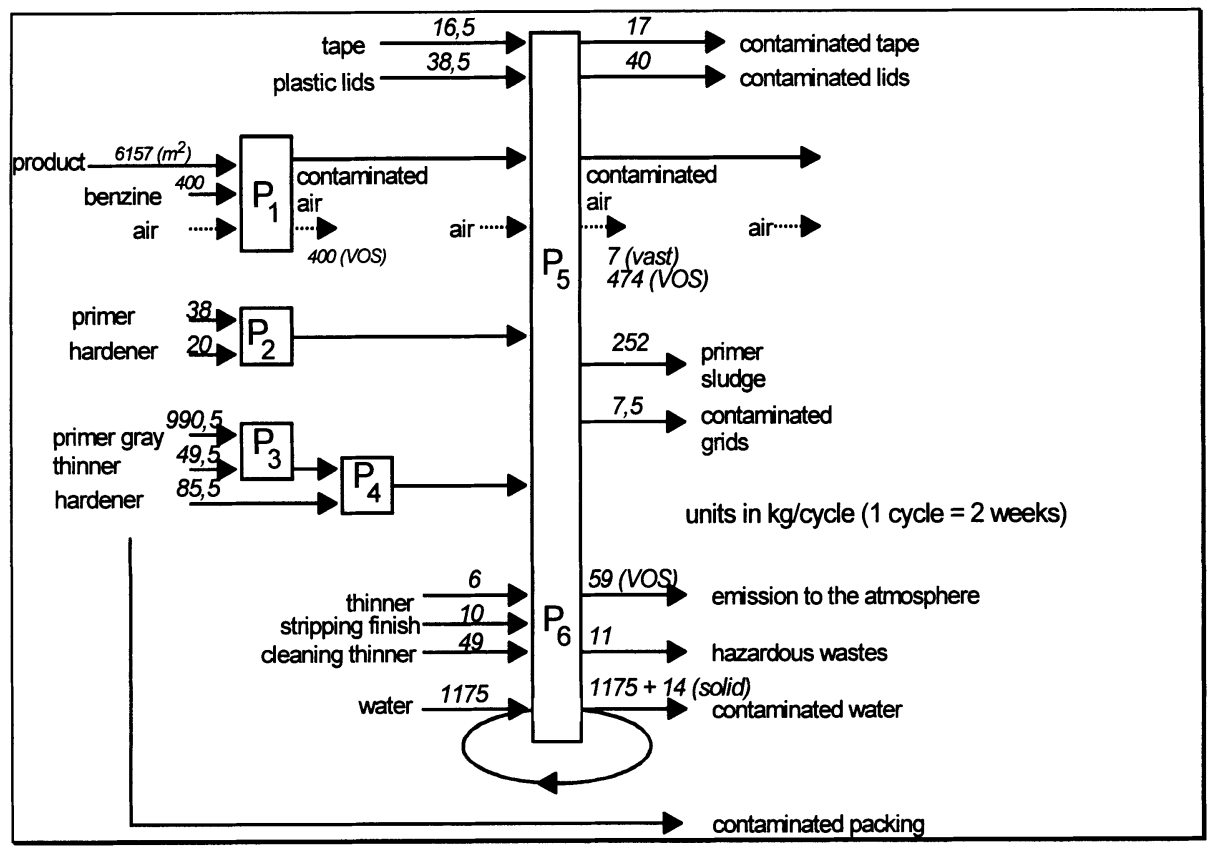

Figure 3. Materials flow related to an engine spray machine.

Table 1. Mass flow proportional to production level.

\begin{tabular}{|c|c|c|c|c|c|c|}
\hline \multirow{3}{*}{$\begin{array}{l}\text { material } \\
\text { (name) }\end{array}$} & \multirow{3}{*}{$\begin{array}{l}\text { input } \\
(\mathrm{kg} / \mathrm{yr})\end{array}$} & \multirow[t]{3}{*}{ on products } & \multicolumn{4}{|l|}{ discharges } \\
\hline & & & \multirow{2}{*}{$\begin{array}{l}\text { hazardous } \\
\text { waste }\end{array}$} & \multirow[t]{2}{*}{ to water } & \multicolumn{2}{|c|}{ to atmosphere } \\
\hline & & & & & solid & volatile \\
\hline benzine & 9600 & - & - & - & - & 9600 \\
\hline -base & 911 & 216 & 94 & 6 & 3 & 592 \\
\hline -hardener & 481 & 228 & 99 & 7 & 3 & 144 \\
\hline polish & & & & & & \\
\hline -base & 23761 & 10020 & 4341 & 295 & 148 & 8957 \\
\hline -thinner & 1200 & - & - & - & - & 1200 \\
\hline -hardener & 2045 & 971 & 419 & 29 & 14 & 612 \\
\hline total & $\overline{37998}$ & 11435 & 4953 & 337 & 168 & 21105 \\
\hline
\end{tabular}

Table 1 shows the mass balance of the materials flows that are proportional to the production level, except the flows of air, water, and products. It depends on production level and product mix, resulting in a total surface (in $\mathrm{m}^{2}$ ) and a distribution in types of primer. A typical case, integrated over a year, has been presented here. 
Table 2 presents the materials balance of the material flows that do not depend on production. They emerge at periodical cleaning programs, e.g. a monthly and a yearly one.

Table 2. Mass flow independent of the production level.

\begin{tabular}{|c|c|c|c|c|c|c|}
\hline \multirow{3}{*}{$\begin{array}{l}\text { material } \\
\text { (name) }\end{array}$} & \multirow{3}{*}{$\begin{array}{l}\text { input } \\
(\mathrm{kg} / \mathrm{yr})\end{array}$} & \multirow[t]{3}{*}{ on products } & \multicolumn{4}{|l|}{ discharges } \\
\hline & & & \multirow{2}{*}{$\begin{array}{l}\text { hazardous } \\
\text { waste }\end{array}$} & \multirow[t]{2}{*}{ to water } & \multicolumn{2}{|c|}{ to atmosphere } \\
\hline & & & & & solid & volatile \\
\hline thinner & 145 & - & 130 & - & - & 15 \\
\hline stripping fluid & 240 & - & 144 & - & - & 96 \\
\hline rinsing fluid & 1170 & - & - & - & - & 1170 \\
\hline total & 1555 & - & 274 & - & - & 1281 \\
\hline
\end{tabular}

Finally, the energy consumption is presented in table 3. In this particular case the energy flows are basically not related to production but depend linearly on production time, except the polish mixers, that are functioning continuously.

From this case, it became evident that mass balances play a valuable role in estimating the environmental impact of production. Complete and actual information to the grade of detail presented above, however, is often hard to obtain. It should be consciously analyzed to which extent aggregation of information may be applied. Additionally, an information system can be of help if it covers both environmental and other material related issues, e.g. purchasing, scheduling, etc.

Table 3. Energy consumption.

\begin{tabular}{|c|c|c|c|}
\hline \multirow{2}{*}{$\begin{array}{l}\text { process } \\
\text { (name) }\end{array}$} & \multirow{2}{*}{$\begin{array}{l}\text { input } \\
\left(G J_{e} / y r\right)\end{array}$} & \multicolumn{2}{|l|}{ output } \\
\hline & & heat to air & heat to water \\
\hline additional ventilation for cleaning & 58 & 58 & - \\
\hline spraying and drying & 94 & 94 & - \\
\hline water-curtain & 10 & - & 10 \\
\hline polish mixer & 12 & 12 & - \\
\hline compressor & 17 & - & 17 \\
\hline lighting & 89 & 89 & - \\
\hline total & 280 & 253 & 27 \\
\hline
\end{tabular}




\section{THE TRANSLATION OF THE PHYSICAL FLOW CONCEPT INTO AN INFORMATION ARCHITECTURE}

In this section, the physical flow concept of mass and energy balances is considered from an information point-of-view. The conceptual model is based on the multi-input multi-output process approach and results in an information architecture, illustrated by a datamodel.

\subsection{Communication view}

Environmental information is required both within the company on different hierarchical levels and by a variety of external stakeholders who act autonomously, so environmental information supports most different needs and interests. Because the field of environmental data requirement is rapidly evolving, environmental information systems should be flexible within a high degree to meet future needs. It is apparent that the manufacturer is benefitted by continuous, and if possible, growing sales, within the constraints of regulations and maintaining a solid and reliable image. From an integral chain control point-of-view, however, constraints will be imposed by suppliers and buyers to prevent this kind of sub-optimalisation. Additionally, those parties in the supply chain will request assurances to secure their position, based on a type of information not necessarily useful to the manufacturer himself. This tension is even more explicit in relation to the government, neighbours and environmental bodies. In this paper, we focus on the manufacturer, in relationship to the parties mentioned above.

The structure of the system and its interface with the users should be according to ISO 14000 standards (ISO, 1992; ISO, 1994) that are presently worked out and will cover the topics: environmental management systems, -auditing, -labelling, -performance standards, harmonisation of life cycle assessment, and guidance for product standards.

\subsection{Multi-input multi-output process approach}

Physical flows are considered as a very elementary and flexible starting point. However, physical data as such cannot be regarded as environmental information. The transformation of physical data, e.g. mass balances, into environmental data can be accomplished by applying the following structure:

1. Basic registration: storage of data resulting from measurements, standards, simulations etc;

2. Interfaces with specific (environmental) applications;

3. Specific applications: ISO-like systems, annual reports.

The tuning of environmental data with production data is achieved in the basic registration, the part that is depicted in this paper. The frequently promoted integration of environmental systems with quality data, health and safety systems etc, fits in this view on level 3 . This can only be realised if the underlying data are available and consistent, and provides that a consistent view on the basic registration is available.

Two approaches to information that play a crucial role are discernable:

1. Information of mainly qualitative character like procedures and instructions that are part of the environmental management system. This information is particularly top-down oriented (from management towards primary process) and can be handled within a workflow management environment. 
Information of principally quantitative nature, reflecting the physical situation of the production system and possessing a bottom-up orientation, thus directed from the primary process towards the management. This study is mainly focused on the latter approach.

Because environmental management systems have a similar structure as other, e.g., quality and safety, management systems, it is highly preferable to combine them. This principle should also govern the structure of information systems. A scheme of the information flows that are related to environmental topics is expressed in figure 4.

Central in this picture is the primary process, represented as a multiple-input multiple-output process with its multiple entering and leaving physical flows. Parallel to it, a physical flow model is

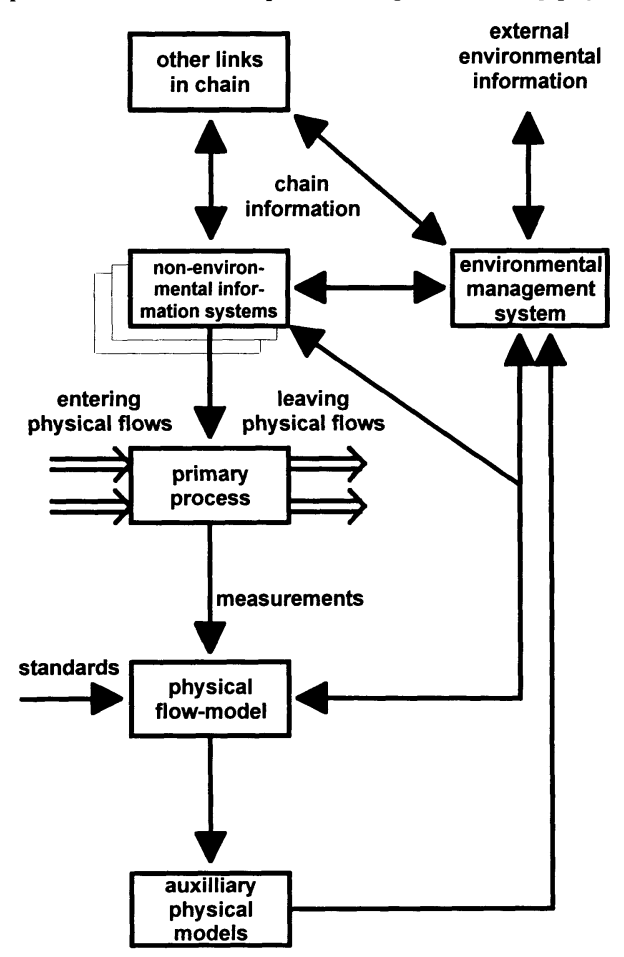
present that meets the requirements of all users of physical information. It is based on standards and it is characterized by internal degrees of freedom that should be adjusted to the reality from time to time. To that purpose, data are transferred to the physical flowmodel that may be the results of measurements, data on stocks, production, routing and so on. Here it becomes clear that also data from non-environmental management systems like production control are transferred to the physical flow model. Within this approach, the environmental management system exhibits a generic structure in common with other management systems and is actually fully integrated with them. As is visualized in fig. 4, the environmental management system generates information for internal use, e.g. for supporting cost accounting, and it may also support chain information systems by exchanging information from and to other links in the chain. Moreover, it should provide information for external use, varying from public annual reports to data in favor of agencies that grant licenses.

Figure 4. Physical information flows.

\subsection{Information architecture}

In this section, the outline for an information (reference) architecture is depicted for the basic registration of an aspect system, in casu an environmental information system. Earlier, it is advocated that an aspect system should be developed as an integral part of the entire enterprise resource planning (ERP) system and thus a number of areas of a customer-oriented organization are involved. (AMR, 1994) summarizes the following functional areas: 
- research and development: the design stage in a product life-cycle approach commits to most of the costs and problems.

- production logistics: this includes (1) materials management, purchasing systems need guidelines and specific data about hazardous materials as a starting point for negotiations with suppliers and to be able to supply data to manufacturing; (2) scheduling and planning: just as a schedule can optimize for bottleneck equipment, it can optimize for minimal pollution; and (3) processing: many companies create reams of process data, nevertheless they cannot stay within their permitted limits permanently. It's not that they don't have the real-time process data they need, they simply don't compile or save the data in a way to turn it into useful information.

- maintenance: the way equipment is running can have a dramatic effect on waste streams. This both holds true for production means and for durable equipment such as airco's being under service by the original equipment manufacturer.

This view is described as the subsystem dimension. A second dimension in ERP-systems is formed by the aspect system, in this case the environmental system. An overview of dimensions is specified below. General for ERP-systems are:

- subsystem: the subsystems are defined as functional areas along the supply chain: engineering, purchasing, manufacturing / processing, warehousing, distribution, sales, service, recycling, ...

- aspect system: an aspect system is defined as that part of the organization $($ system,...) belonging to the specified aspect, across all subsystems. The following aspects are distinguished: logistics, quality, health, safety, legislation, economics,.....

- branch: the type of product highly influences the type of possible environmental burden. Important categories are: chemical, food and beverage, automotive, electronics...

- control level: the level of control influences the level of detail required. The classification originates from general enterprise control: strategic, tactical, operational and instrumental.

- implementation level: state independent data: norm values (BOM/formula) or norm values (routing) and state dependent data: measurements and simulations.

Environmentally specific orientation:

- environmental function: there are two main differences: logistic (l) versus registration (r) aspects, and quantitative (qn) versus qualitative (ql) data. We distinguish product waste (both l-qn and r-qn), emissions (r-qn), hazardous materials (both l-qn and r-qn), packaging (both l-qn and r$\mathrm{qn})$, nuisance ( $\mathrm{r}-\mathrm{ql}$ ).

- environmental application: environmental annual report, environmental management / assurance system, permits, measurements, registrations...

- environmental solution: materials and energy balance, environmental costing tracking and tracing and reverse logistics.

\subsection{Towards an environmental datamodel}

As was stated in the conclusion of section 3, a supporting information system is helpful to realize the implementation of mass balances. In this section the datamodel for CAR-E is given, based on the mass balance model described earlier.

At first instance the system is meant to be a prototype for internal use and therefore no attention is paid to the communication infrastructure and integration with other aspect systems. The system infrastructure focuses in particular on the basic registration based on mass balances, and includes the operational and instrumental level of material management, scheduling, planning, manufacturing and maintenance. In figure 5 the main entities of the datamodel and its relationships are shown. 
The different flows as were distinguished in figure 2 can be found in this model. The effects on the environment are modeled as dependent only from the production system. There is no difference between the situation in which the environmental burden is desired or not. There are cases however where not all effects on the environment have to be accounted for. When for instance a byproduct is one of the results of the production system, then following the model in figure 5 this is con-

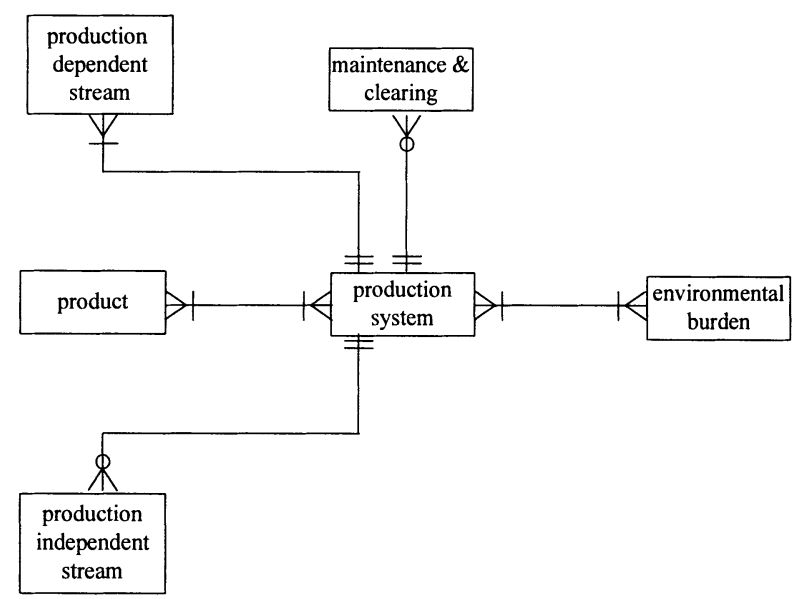

Figure 5. Datamodel of the environmental information system for CAR-E.

sidered as a burden for the environment. It is not counted as such however when e.g. another firm can use it for its production system. The datamodel in figure 6 is more closely to this situation. There a created product can be a principal product, a desired by-product or an undesired by-product. The environmental burden of the model in figure 5 is connected to the undesired produced by-product.

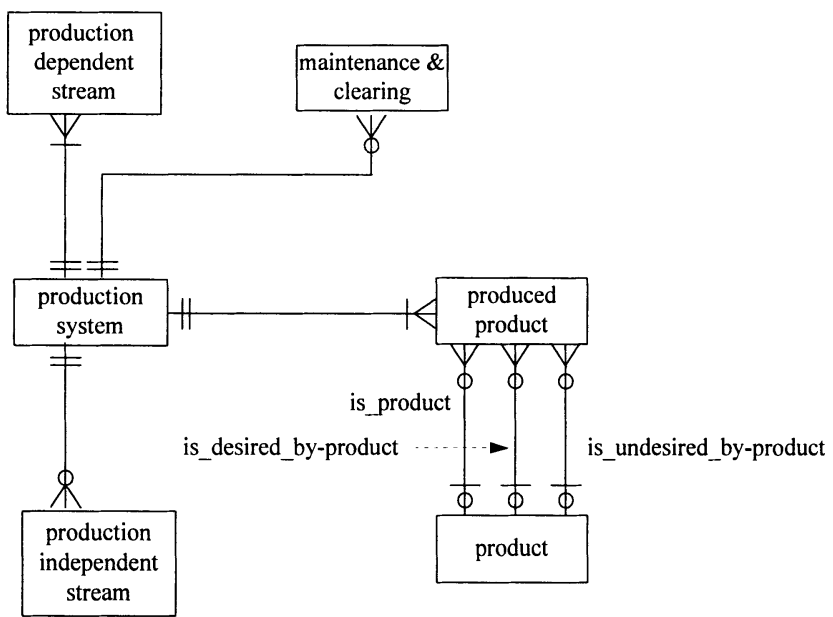

Figure 6. Proposed datamodel for an environmental information system. 
As a preparation to apply environmental functionality to management information systems, the essentials of this functionality have been analyzed. A top-down and a bottom-up approach are discerned here, referring to respectively workflow management and processing of information from the primary process.

It appeared that the essentials of the latter aspect are based on physical flows and a general description of production processes by a multiple-input multiple-output approach. Although not explicitly discernible within the usual structure of production control systems, virtually all information on production is based on physical flows. According to this observation, a novel approach to structuring information systems is proposed that justifies the position of physical flows in the information system and that leads to similarity on structure for the information (sub)systems. It implies that environmental information systems should not be added as a separate module, but should be integrated in the present modules, especially the operational - logistic- information, by adding new attributes to existing entities. To that order, the structure of the logistics information system should be modified to by-pass the artificial difference between discrete manufacturing and process industry by universal application of multiple-input multiple-output models in all types of production. Once performed this restructuring, derivation of environmental information has become a standard task.

\section{REFERENCES}

AMR report (1994) No-waste systems: using manufacturing systems for environmental advantage and vice versa, Advanced Manufacturing Research, Massachusetts.

Browne, J., Sackett, P.J. and Wortmann, J.C. (1995) Future manufacturing systems: towards the extended enterprise, Computers in Industry, 25, 235-254.

Graedel, T.E. and Allenby, B.R. (1995) Industrial ecology, Prentice Hall, Englewood Cliffs, NY.

Guineé, J.B., Udo de Haes, H.A. and Huppes, G. (1993a) Quantitative life cycle assessment of products, 1: Goal definition and inventory, Journal of Cleaner Production, 1(1), 1993, 3-13.

Guineé, J.B., Heijungs, R., Udo de Haes, H.A. and Huppes, G. (1993b) Quantitative life cycle assessment of products, 2: Classification, valuation and improvement analysis, J. Cleaner Prod., $1(2), 81-91$.

Inoue, H., Nakazawa, Y. and Ohyama, N. (1992) Ecofactory -concept and R\&D themes, report of Mechanical Engineering Laboratory, Tokyo.

ISO (1992) Sustainable industrial development: a role for international standards, ISO-bulletin, 2-7.

ISO (1994) Progress on ISO 14000, Environmental Manager, 8.

Kandelaars, P.P.A.A.H., Jansen, M.H., Lambert, A.J.D. (1996) Survey of physical flow models focusing on the environment, Ecological Economics, forthcoming.

Kandelaars, P.P.A.A.H. and Bergh, J. Van den (1996) Materials-product chains: theory and an application to zinc and PVC gutters, Environmental and resource economics, forthcoming

Lambert, A.J.D. (1995) Optimal disassembly of complex products, International Journal of Production Research, forthcoming.

Nemerow, N.L. (1995) Zero pollution for industry, Wiley-Interscience, New York.

Splinter, M.A.M. (1994) An energy model of production systems, in Proceedings of the first European Congress on Economics and Management (ECEMEL), Rio Tinto (Portugal).

Wang, M.H. and Johnson, M.R.(1995) Design for disassembly and recyclability: a concurrent engineering approach, Concurrent engineering, 3(2), 131-134.

Wolters, W.T.M. (1994) Sustainable industrial production: an energy perspective, Thesis, Eindhoven University of Technology. 
Wolters, W.T.M., Lambert A.J.D. and Claus J. (1995) Sequencing problems in designing energy efficient production systems, International Journal of Production Economics, 41, 405-410.

Wong, S., Fu, J.C. and Troy, C.A. (1993) A product assembly and restoration planning system for ecologically conscious factories, in Information infrastructure systems for manufacturing (ed. Yoshikawa H. and Goossenaerts J.) Proceedings of DIISM'93, Tokyo, North-Holland, Amsterdam, 319-329.

\section{BIOGRAPHY}

Fred Lambert is assistant professor at the Eindhoven University of Technology, section Energy and Environment of the faculty Technology Management. His research interest is in the field of chain management in relation to energy and the environment.

Monique Jansen received her masters degree in Computer Science in 1993. Currently, she is a Ph.D. candidate at the Eindhoven University of Technology in the field of environmental information systems from a business point-of-view. In this research she is cooperating with Baan Company, a manufacturer of Enterprise Information Systems.

Robert Schuwer is assistant professor at the Eindhoven University of Technology, section Information and Technology of the faculty Technology Management. He finished his Ph.D.-thesis in 1993 on a subject in the area of knowledge base systems. His current research interest includes IT-based solutions for knowledge management, intelligent production planning and support of professionals with advanced IT.

Maarten Splinter is assistant professor at the Eindhoven University of Technology, section Energy and Environment of the faculty Technology Management. His research interest is in the field of energy systems. 